\title{
Finite Element Analysis and Evaluation of Bogie Frame for Passenger Locomotive based on Reliability
}

\author{
Yanliang Wang, Junfang Xue*, Xiufen Zhang, and Lichun Chen \\ College of Mechanical Engineering, Inner Mongolia University of Technology, Hohhot, 010051, China
}

\begin{abstract}
Passenger locomotives are developing rapidly in the direction of high speed, high power, energy saving, environmental protection, and light weight. In order to avoid locomotive failures such as fatigue fracture, the requirements for reliability and fatigue strength are becoming increasingly higher. The passenger locomotive running steadily and safely mainly depends on whether the design of the steering frame structure is reasonable. Based on the locomotive bogie by 3D solid modeling, the static strength and modal analysis of ANSYS finite element analysis software is applied to the reliability of the operation stage to make judgments and a reliability evaluation model frame is set up based on finite element analysis.
\end{abstract}

Keywords: reliability; finite element analysis; static strength; fatigue damage; evaluation

(Submitted on October 15, 2018; Revised on November 12, 2018; Accepted on December 7, 2018)

(C) 2019 Totem Publisher, Inc. All rights reserved.

\section{Introduction}

Under the new normal state, the railway freight transportation management system, equipment technology, and change of market demand have strongly collided for many years, and the railway freight transportation and its technical development have faced severe challenges. Entering the "13th Five-Year", China's economy is still developing at an intermediate speed, and the overall social logistics are still growing at a high speed. The railway freight has its own unique advantages compared with highway, water transportation, and aviation.

With the development of urban rail transit, electric locomotives are being widely used in rail traffic. According to the statistics of the National Development and Reform Commission, the number of new electric locomotives from 2015 to 2017 maintained an average annual growth of about $15 \%$. However, most of the locomotive failures are directly or indirectly related to bogies. Therefore, research on the reliability of locomotive bogie frames is particularly important [1-3].

The bogie is one of the most important components of EMU. It has three functions of driving, supporting, and guiding, which determine the safety and stability of train operation, as shown in Figure 1. The bogie frame of an electric locomotive is one of the most important parts of the bogie, and it is also the installation foundation of the other parts of the bogie. It not only bears the weight of parts, such as the car body, traction motor, and brake device, but also is influenced by the dynamic loads from different environments and different working conditions and bears the tasks of transmitting traction, braking force, lateral force, and vertical force [4].

The reliability of the bogie frame is directly related to the performance of the whole locomotive. Under the special conditions of heavy load, braking, and turning, the locomotives are subjected to repeated stress and heavy load impact of alternating stress, which is prone to fatigue deformation, fatigue crack, and failure [5]. Therefore, when designing the frame, it should not only ensure the interface size is reasonable and accurate, but also work safely and reliably in a given environment, and more importantly, it is necessary to meet the strength requirements for operation and ensure the stability and safety of the locomotive. In addition, in order to avoid accidents, it is necessary to ensure the reliability in the whole

\footnotetext{
* Corresponding author.

E-mail address: xuejunfang@tsinghua.org.cn
} 
process of frame design, manufacture, actual operation, maintenance management, and so on. Among them, the research on reliability in the operation stage is the most important. In order to achieve the transformation from ex-post maintenance to pre-maintenance, we must evaluate the reliability of the architecture in operation [6].

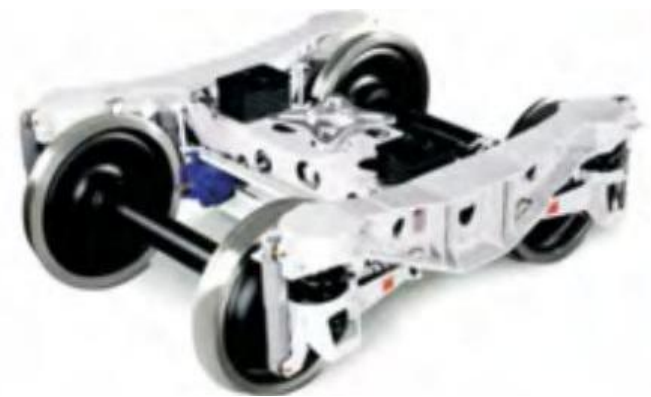

Figure 1. Power locomotive bogie

At present, there are few studies on the reliability of locomotive frames, and their reliability is directly related to people's travel safety and ride experience. Therefore, this paper is based on the $200 \mathrm{~km} / \mathrm{h}$ passenger electric locomotive bogie frame as the research object. Through three-dimensional solid modeling and analysis of the static strength and modal of the frame, it provides a reference for the evaluation of structural design and operation reliability and establishes a frame reliability evaluation model based on finite element analysis.

\section{Frame Structure and Force of Locomotive Bogie}

\subsection{The Structure of Frame}

In order to adapt to the operation of large axle loads and optimize the dynamic performance, the steering frame gives up three pieces of its frame structure, which consists of two symmetrical side beams, end beams, traction beams, and central beams.

The bogie frame of the $200 \mathrm{~km} / \mathrm{h}$ passenger locomotive adopts an approximate " $\mathrm{H}$ " shaped structure with transverse beams. It consists of two measuring beams with symmetrical sides and two beams with the same structure. Each beam has a certain number of partitions inside it, which is used to enhance the torsional stiffness of the frame. Main components include the spring suspension, shock absorber seat, traction rod base, anti-rolling torsion bar support, brake mounting base, and motor hanger. The total length of the frame is $4610 \mathrm{~mm}$, the total width is $2350 \mathrm{~mm}$, and the overall structure diagram of the frame is shown in Figure 2.

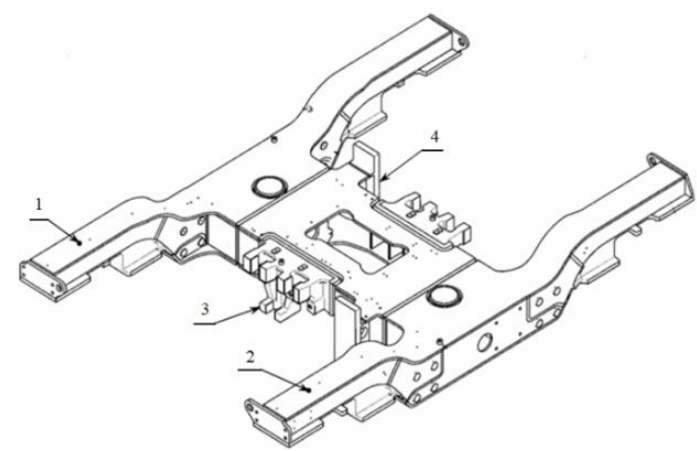

1. The right side beam; 2 . The left side beam; 3 . The first crossbeam; 4 . The second crossbeam Figure 2. Frame structure diagram of passenger $200 \mathrm{~km} / \mathrm{h}$ electric locomotive bogie

The main structure of the frame is welded by a $16 \mathrm{Mn}$ steel plate, and the transverse beam is connected by a seamless steel tube to the side beam. $16 \mathrm{Mn}$ steel is a kind of low alloy and high strength structural steel. It has the characteristics of light quality, material saving, and excellent weldability. The performance parameters of $16 \mathrm{Mn}$ steel are shown in Table 1.

Table 1. Material properties of $16 \mathrm{mn}$ steel

\begin{tabular}{|c|c|}
\hline Table 1. Material properties of $16 \mathrm{mn}$ steel \\
\hline Material Properties & Value \\
\hline Elastic Modulus (MPa) & $2.06 \mathrm{e}+05$ \\
\hline Poisson Ratio & 0.3 \\
\hline Density $\left(\mathrm{kg} \cdot \mathrm{m}^{-3}\right)$ & 7300 \\
\hline Yield Limit $(\mathrm{MPa})$ & 345 \\
\hline
\end{tabular}




\subsection{Analysis and Calculation of Structural Force}

When the locomotive runs normally, the bogie frame is mainly subjected to three loads in the vertical, horizontal, and longitudinal directions, and the stress distribution of each load and the combined working conditions are calculated respectively $[5,7]$.

The vertical static load includes the gravity of the car body, axle, bogie, and passengers. The lateral load includes the wind force and centrifugal force of the car body. The longitudinal load has the traction force, friction force, and inertia force when braking. In addition, the dynamic load caused by vibration and shock is also included. The load and constraints are shown in Figure 3, and the technical parameters of the bogie frame are shown in Table 2.

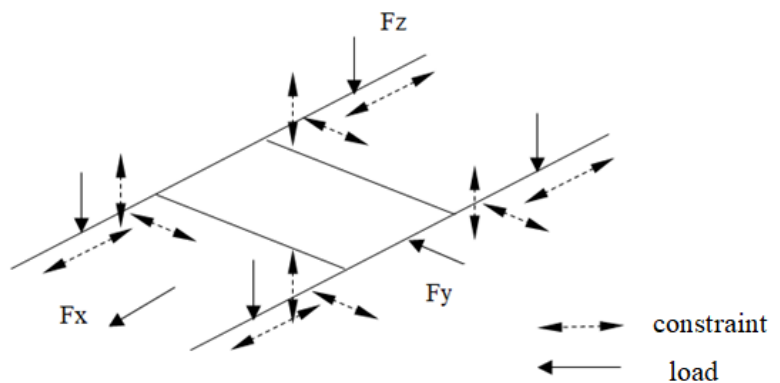

Figure 3. A schematic diagram of the force of the bogie frame of a passenger locomotive

Table 2. Technical parameter table of bogie frame

\begin{tabular}{|c|c|}
\hline Parameter & Value \\
\hline Gross rail load on Axle $(t)$ & 21 \\
\hline The weight of Bogie $(t)$ & 26 \\
\hline Weight with full Equipment $(t)$ & 138 \\
\hline Running Speed $\left(\mathrm{km} \cdot \mathrm{h}^{-1}\right)$ & 200 \\
\hline Traction Force $(\mathrm{kN})$ & 285 \\
\hline
\end{tabular}

The load analysis and parameters can be used to calculate the load of the frame during the operations of the simulated locomotive. The results of the vertical, horizontal, and longitudinal loads are calculated, as shown in Table 3.

Table 3. Load calculation value
\begin{tabular}{|c|c|}
\hline Load type & Value \\
\hline Vertical load $(\mathrm{kN})$ & 211 \\
\hline Lateral load $(\mathrm{kN})$ & 116 \\
\hline Longitudinal load $(\mathrm{kN})$ & 142 \\
\hline
\end{tabular}

\section{Strength Calculation of Frame Finite Element}

\subsection{Architecture Modeling}

In Pro-E, the three-dimensional solid modeling of the locomotive steering frame is modeled by the thin plate element based on the actual size, as shown in Figure 4.

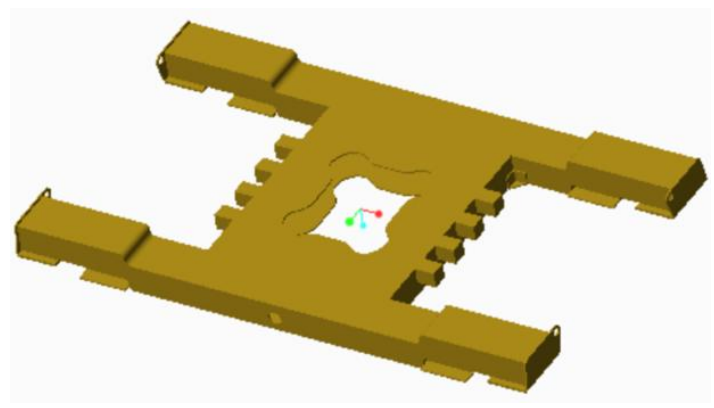

Figure 4. Three-dimensional model of locomotive bogie frame 


\subsection{Static Strength Analysis of Frame}

The three-dimensional model of the constructed frame is introduced into the finite element analysis software ANSYS Workbench 17.0, the material attributes are defined according to Table 1, and the static strength analysis is carried out.

For the frame finite element model, the two mesh generation methods, mapped grid and hexahedral element free grid, are used to divide the mesh, smooth the transition at the circular arc, and refine the mesh locally. The mesh results are shown in Figure 5.

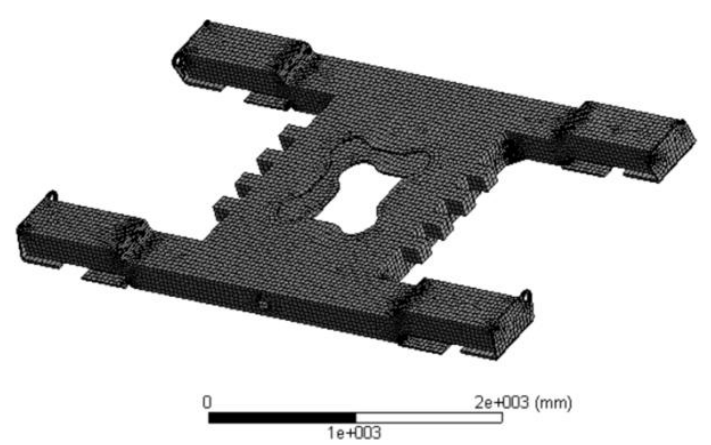

Figure 5. Grid division of locomotive bogie frame

According to the actual conditions of the welded steel structure frame applied load and constraints, load the active role in the force on the surface of constraints imposed on the passive force at the start, perform calculations, and finally obtain the results of finite element analysis, including the equivalent stress diagram and total deformation effect, as shown in Figure 6.

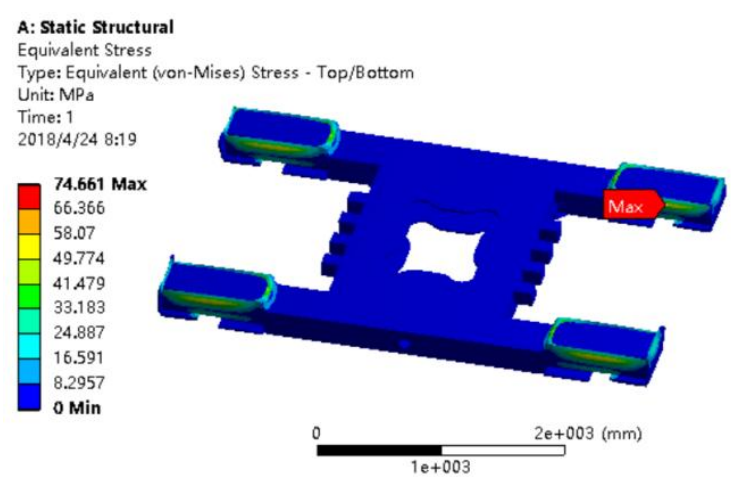

(a) Equivalent stress

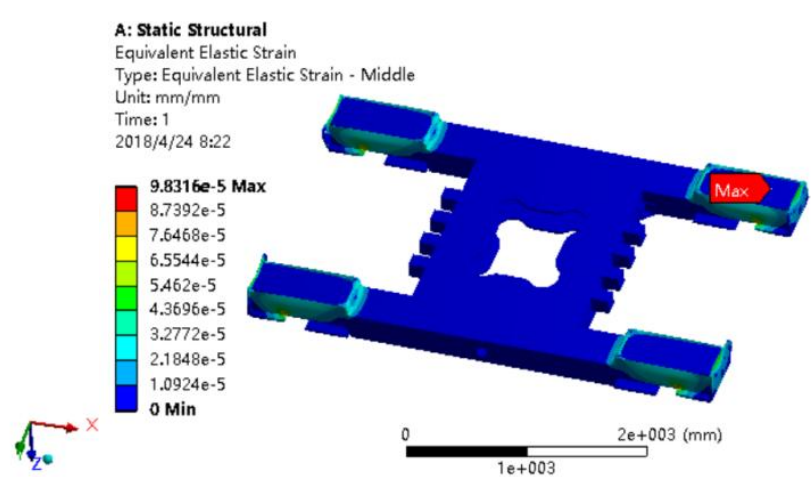

(b) Equivalent elastic strain

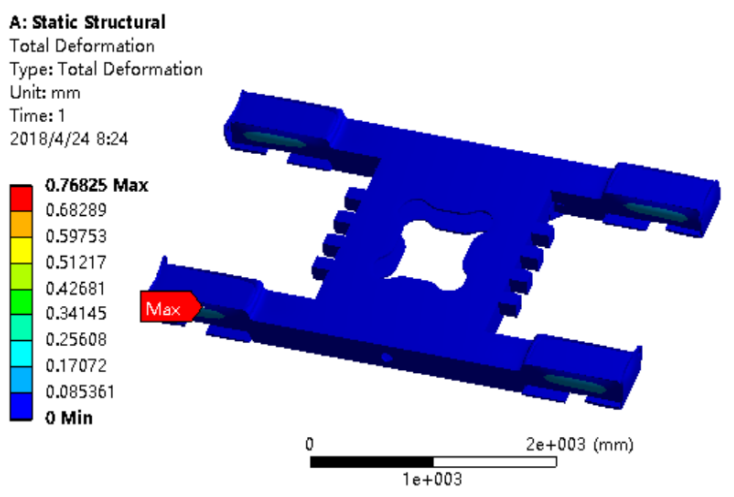

(c) Total deformation

Figure 6. The result diagram of finite element analysis

It can be known from Figure 6 that, firstly, the maximum stress is located in the inner side of the beam end and its value is $74.661 \mathrm{MPa}$. This is less than the yield strength limit, which meets the requirements of reliability. Secondly, the equivalent plastic strain occurs at the end face of the beam, and the deformation is small. Thirdly, the maximum deformation of the 
frame is located outside the beam end, and the maximum deformation is $0.768 \mathrm{~mm}$.

The results show that the places where deformation and maximum stress occur easily are located at the ends of the two sides of the beam, the transition of the arc and the place where the weld is. These places also need to focus on the research of the reliability of the structure.

\subsection{Modal Analysis of Frame}

In the process of starting, driving, turning, and braking, the bogie frame will bump and vibrate. In most cases, vibration is harmful. It will affect the normal operation and use of locomotives. Therefore, to analyze the reliability of the structure, we must consider the effects and hazards caused by the vibration to confirm whether the internal structure of the bogie system has any problems such as failure, loosening, and wear, so as to provide reference for subsequent troubleshooting and maintenance [8-10]. The material attributes are defined according to Table 1, as shown in Figure 7. The modal analysis of the frame is shown in Figure 8.

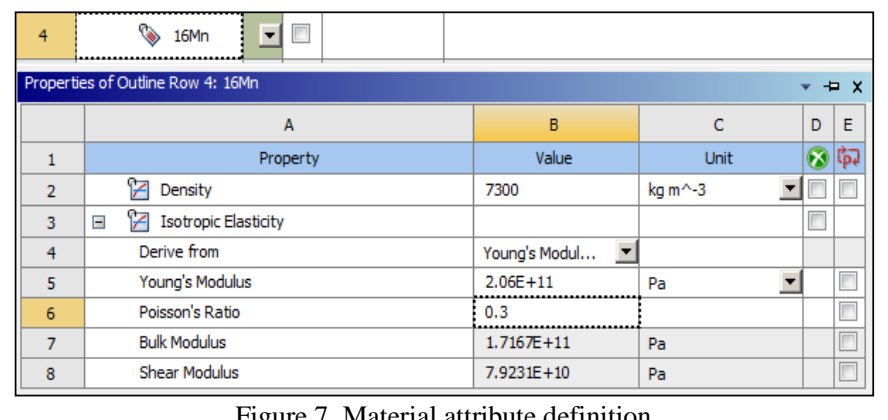

From Figure 8, it is known that in the turbulence and vibration of the frame, the place where the vibration and deformation are easy to occur is located in the side beam and the end beam, and the closer to the edge, the greater the vibration. Therefore, by changing the mass distribution and weight reduction of the side beam, the purpose of avoiding resonance and reducing the impact is achieved, and the reliability of the frame can be enhanced.

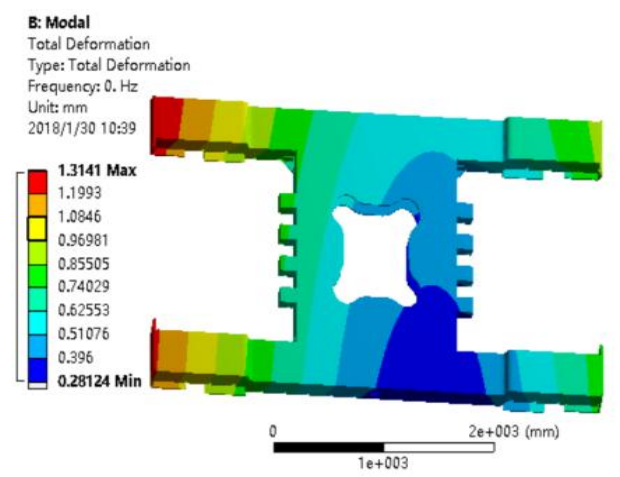

(a) First order mode of vibration

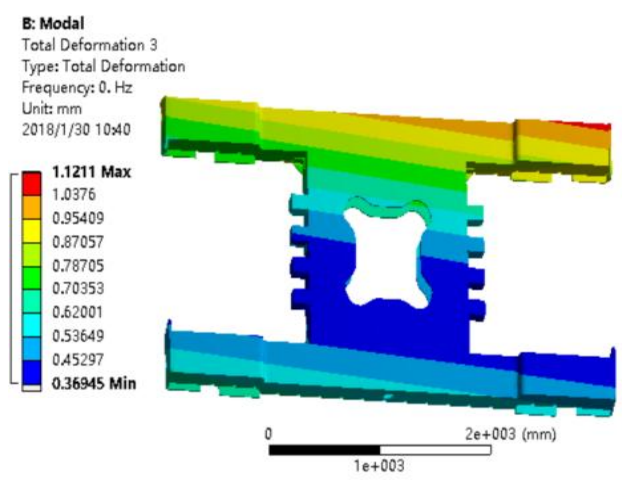

(c) Three order mode of vibration

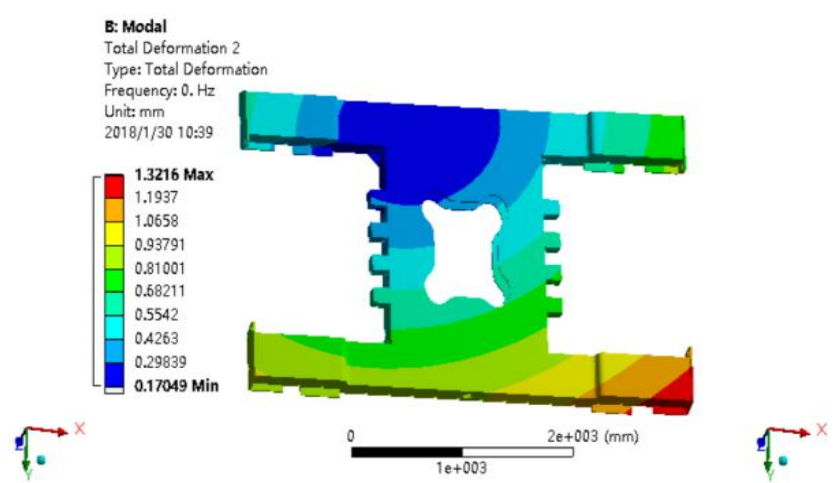

(b) Two order mode of vibration

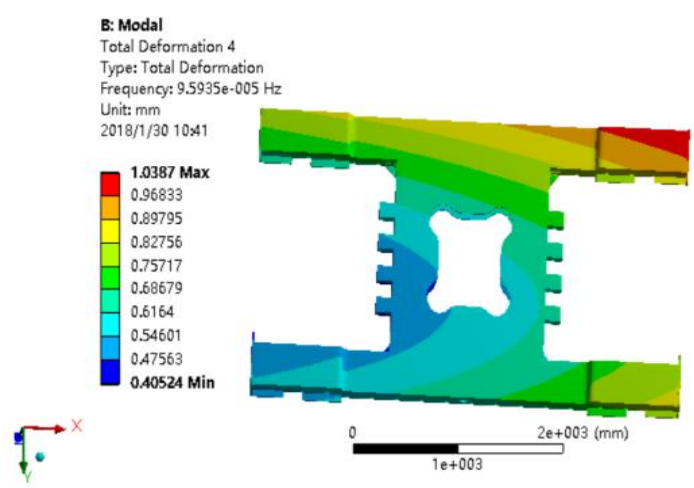

(d) Four order mode of vibration

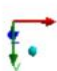




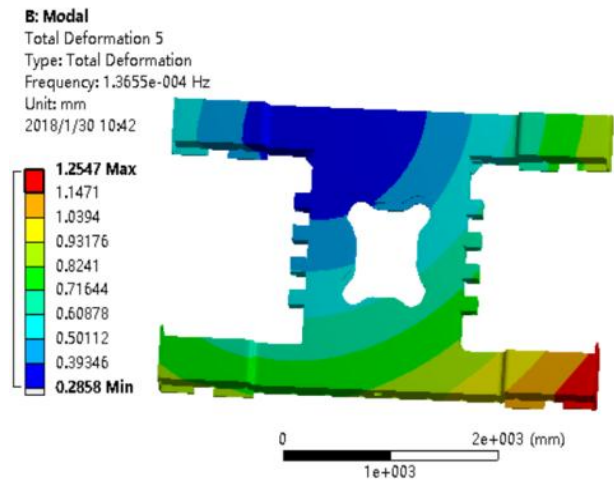

(e) Five order mode of vibration

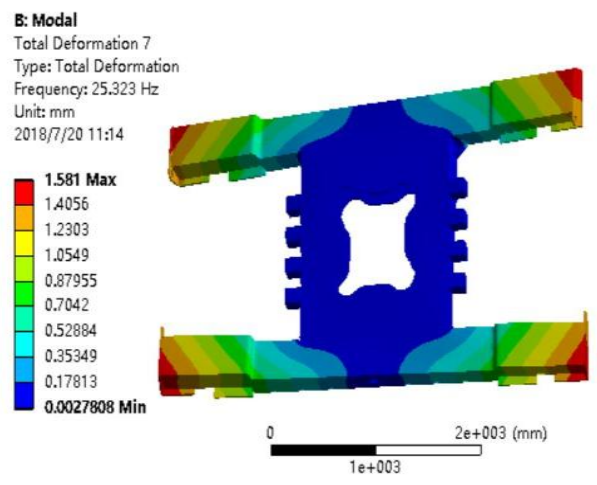

(g) Seven order mode of vibration

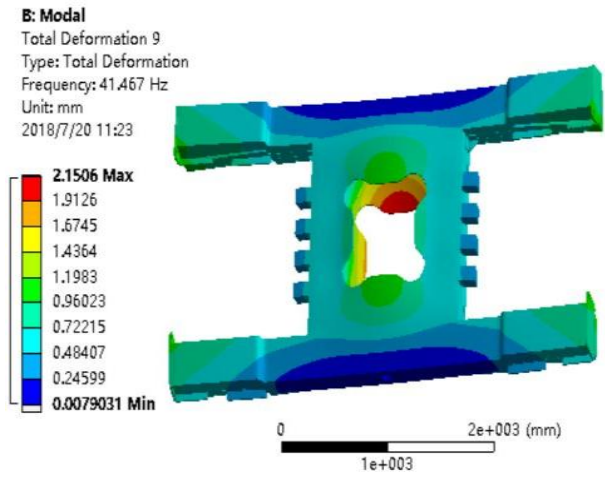

(i) Nine order mode of vibration

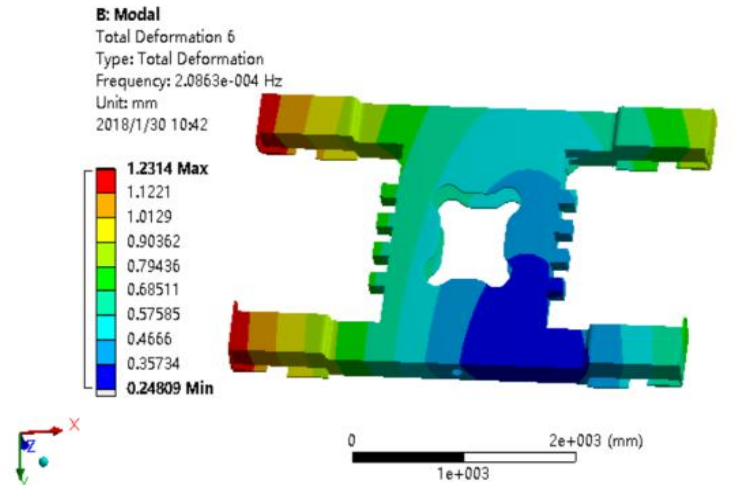

(f) Six order mode of vibration
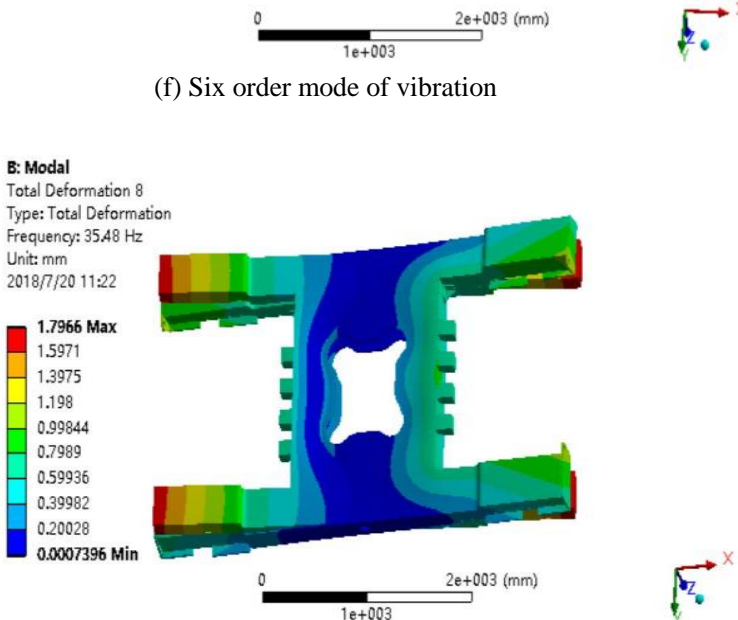

(h) Eight order mode of vibration

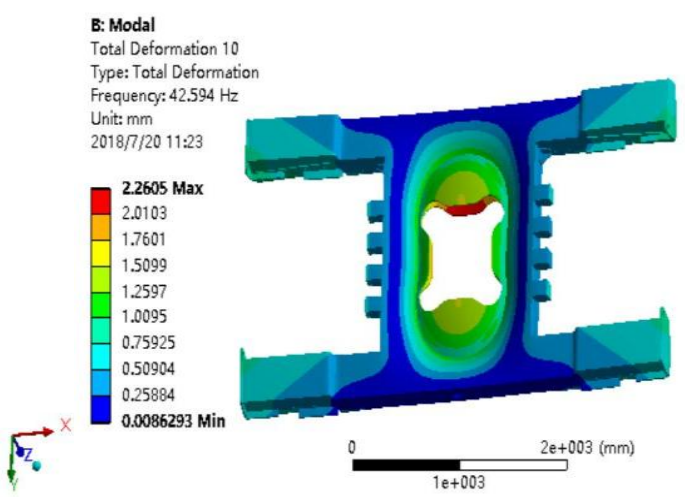

(j) Ten order mode of vibration
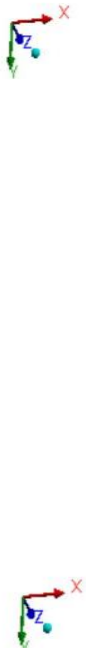

Figure 8. Modal shape diagram of frame

According to the theory of modal analysis, the free modal of the frame finite element model is analysed, and the natural frequency and vibration mode of the former 10-steps mode of frame are computed. At the same time, the structural dynamic characteristics of the frame are determined and the weak of frame in the vibration is pointed out, which will provide reference for improving the design of dynamic characteristics, effectively preventing the phenomenon of resonance. Thus, it is significant for further dynamic analysis.

\section{Reliability Model of Truck Frame}

Based on the previous finite element analysis of the locomotive running stage, the actual force and vibration of the frame are simulated, providing the conditions for the reliability evaluation of the frame. The reliability assessment of specific parts is a personalized problem. It is necessary to consider the performance of the components itself as well as the use and maintenance performance of the specific working conditions [11-12].

In this paper, the reliability model of the locomotive steering frame is established. Combining the experience with the 
actual situation, the reliability of the frame is evaluated comprehensively to reduce the failure of the frame. The results provide a theoretical basis for the reliability test of locomotive bogie frames.

\subsection{Influence Factors of Reliability of Locomotive Bogie Frame}

In various stages of production, operation, and maintenance, the reliability will be influenced by the quality of the parts themselves, the existing technological level of the factory, the specific operation environment, and the maintenance [6, 1315]. Refer to the relevant information and combine the actual situation to determine the influence factors of reliability, as shown in Figure 9.

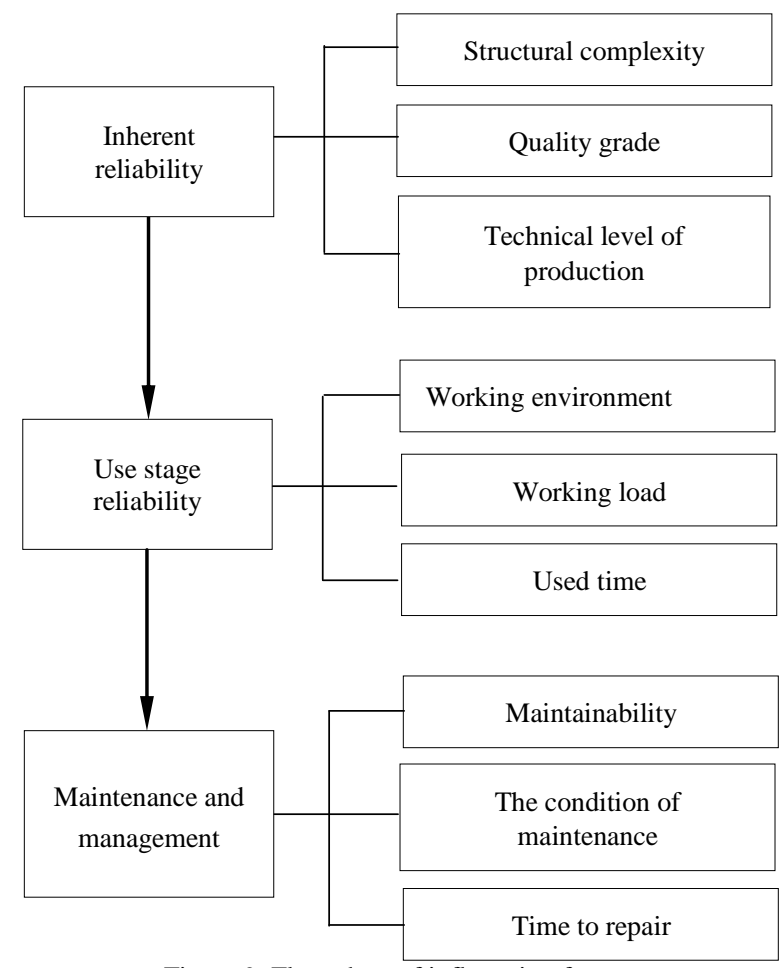

Figure 9. Flow chart of influencing factors

\subsection{Establishment of Structural Reliability Model}

This paper is based on the theory of matter element, fuzzy evaluation, and analytic hierarchy process [5]. The reliability model of the framework is established from three aspects of the inherent reliability, the use stage, and the maintenance management stage. These three factors are chronological in the whole life cycle [16-18]. Only when the reliability of this stage is satisfied can the reliability of the next stage be considered.

First of all, the inherent reliability of the framework is a prerequisite for judging the overall reliability. Then, the reliability of the service stage is evaluated. This stage is very important. Finally, in the aspect of maintenance management, the reliability evaluation is carried out to ensure the safety and reliability of the locomotive frame.

If the three aspects meet the requirements of reliability, the model is established by the matter element theory, and then according to the weight distribution of AHP and the quantitative calculation of fuzzy evaluation, the overall scheme of the reliability of the selected frame is judged and improved [19]. Finally, determine whether the frame meets the requirements and obtain the size of the reliability.

Based on the above analysis, the overall evaluation model of locomotive frame reliability is obtained, as shown in Figure 10 below.

(a) The reliability evaluation model of the frame is shown as follows: 


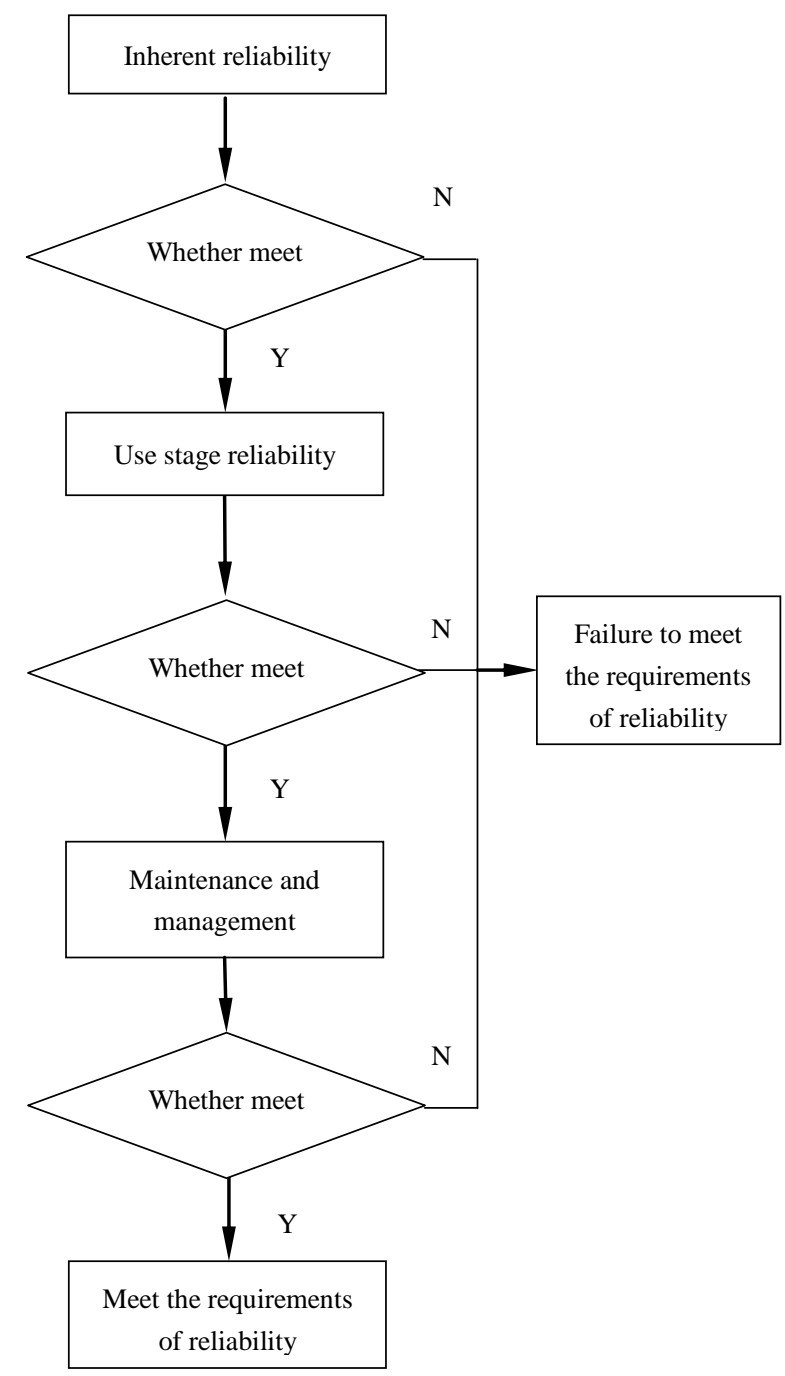

Figure 10. Flow chart of structural reliability evaluation

(b) According to the matter element theory, a matter element model is set up as follows:

$$
R=(G, r, v)=\left[\begin{array}{lll}
G & r_{1} & v_{1} \\
& r_{2} & v_{2} \\
& r_{3} & v_{3}
\end{array}\right]
$$

In the formula, $G$ is a classical domain, $r_{1}, r_{2}$, and $r_{3}$ are the evaluation index, and $v_{1}, v_{2}$, and $v_{3}$ are the actual values of the corresponding evaluation index.

(c) Determine the correlation function: the corresponding formula can be obtained from the definition of the middle distance in mathematics.

$$
\begin{gathered}
\rho\left(r_{i}, X_{0 i}\right)=\left|r_{i}-\frac{a_{0 i}+b_{0 i}}{2}\right|-\frac{1}{2}\left(b_{0 i}-a_{0 i}\right) \\
\rho\left(r_{i}, X_{p i}\right)=\left|r_{i}-\frac{a_{p i}+b_{p i}}{2}\right|-\frac{1}{2}\left(b_{p i}-a_{p i}\right)
\end{gathered}
$$


In this paper, the following function is used to solve the value of the correlation function:

$$
K_{i}\left(r_{i}\right)=\left\{\begin{array}{c}
\frac{\rho\left(r_{i}, X_{0 i}\right)}{\rho\left(r_{i}, X_{p i}\right)-\rho\left(r_{i}, X_{0 i}\right)}, r_{i} \notin X_{0 i} \\
\frac{-\rho\left(r_{i}, X_{0 i}\right)}{\left|X_{0 i}\right|}, r_{i} \in X_{0 i}
\end{array}\right.
$$

In the formula, $r_{i}$ represents the value of each evaluation index of the framework to be evaluated, $i=1,2, \cdots, n$; $\rho\left(r_{i}, X_{0 i}\right)$ represents the distance between point $r_{i}$ and the valid interval $X_{0 i}=(a, b)$.

(d) According to the analytic hierarchy process (AHP) and fuzzy evaluation, the evaluation coefficient of each evaluation index is determined. The following transformation is made to the judgment matrix A, the initial weight is calculated by formula (3), and formula (4) is normalized.

$$
\begin{gathered}
W_{i}^{\prime}=\left(\prod_{j=1}^{n} a_{i j}\right)^{1 / n}, i=1,2, \cdots, n \\
W_{i}=\frac{W_{i}^{\prime}}{\sum_{i=1}^{n} W_{i}^{\prime}}
\end{gathered}
$$

(e) A comprehensive evaluation model of the framework is established.

$$
K(p)=\sum_{i=1}^{n} W_{i} k_{i}\left(v_{i}\right)
$$

In the formula, $n$ represents the number of reliability evaluation indexes, $W_{i}$ indicates the weight value of the evaluation index, and $k_{i}\left(v_{i}\right)$ indicates the value of the correlation function of the evaluation index. Only when $K(p)>0$ is satisfied is the reliability of the frame in line with the requirements, and the greater its value, the better the reliability.

\section{Conclusions}

(1) Through the static strength analysis and modal analysis of the frame, the maximum value of static stress appears at the junction of the side beam and the cross beam of the column. There is an obvious stress concentration in here. In addition, under the action of alternating stress, this place will suffer fatigue damage first. Thus, in order to avoid the occurrence of fatigue damage and improve the reliability of the frame, we need to improve the strength of the side beam and welding site and minimize the impact of emergency braking and heavy hauls.

(2) In view of the reliability problem where the locomotive bogie frame is in the actual operation stage caused by fatigue failure and shock vibration, the reliability analysis model of the frame based on finite element analysis is established in this paper. The model starts with the reliability of a single component and provides a reference for the analysis and research of the reliability of the individual parts.

(3) With the rapid development of rail transit, the reliability of locomotive bogie frames has become very important. In order to make the frame reliability model more accurately reflect the actual situation, we need to use finite element analysis software and field monitoring data to simulate the specific working conditions and perform specific assessments and optimization according to the reliability model.

(4) In order to ensure the reliability of the frame in the operation process, the allowable fatigue strength of the base material and the weld in the random variable of the structural reliability should be improved from the material selection of the frame and the control of the welding process, while the load on the two line air spring, lateral stop, and gear box is set up in the frame. The influence of them should be fully considered in order to improve the fatigue resistance of the frame. 


\section{Acknowledgements}

This research was financially supported by the National Science Foundation of China (No. 51565044).

\section{References}

1. J. W. Wang and Z. G. Zhang, "The Foundation of Reliability Engineering," Science Press, Beijing, China, August 2013

2. Y. M. Zhang, "Connotation and Development of Mechanical Reliability-based Design," Journal of Mechanical Engineering, Vol. 46, No. 14, pp. 167-188, 2010

3. Y. M. Zhang, "Review of Theory and Technology of Mechanical Reliability for Dynamic and Gradual Systems," Journal of Mechanical Engineering, Vol. 49, No. 20, pp. 101-114, 2013

4. H. B. Hu, W. D. Shao, and S. F. Xu, "Technology Status and Development of Fast Freight Car Bogies at Home and abroad," Railway Vehicle, No. 12, pp. 4-9, 2015

5. F. Guo, J. X. Guo, W. L. Zhang, et al., "Passenger Transport 160 km/h Electric Locomotive Bogie Frame Reliability Analysis," Railway Locomotive and Motor Train, No. 6, pp. 29-32, 2016

6. J. Jia, T. Yang, Y. Yang, et al., "Research on Dynamic Programming of the Series Manufacturing System Reliability Allocation," Journal of Convergence Information Technology, Vol. 7, No. 7, pp. 17-25, 2012

7. D. W. Coit, Q. M. Feng, and H. Peng, "Component Reliability Criticality or Importance Measures for Systems with Degrading Components," IEEE Transactions on Reliability, Vol. 61, No. 1, pp. 4-12, 2012

8. Z. X. Du, Q. G. Hu, and X. G. Zhu, "Modal Analysis of Bogie Frame of Cross Seat Monorail Vehicle," Mechanical Design and Manufacture, No. 11, pp. 222-223, 2011

9. Q. Li, Y. M. Peng, and M. Yang, "Static Strength and Fatigue Strength Analysis and Modal Analysis of Bogie Frame of $30 \mathrm{t}$ axle Load Electric Locomotive," Railway Locomotive and Rolling Stock, No. 3, pp. 18-22, 2014

10. T. Li, "Optimization of High Speed AC Drives Co-Co Locomotive Steering Frame Optimization," Chengdu: Southwest Jiao Tong University, 2007

11. H. G. Cao, Z. J. He, and Z. Sun, "Journal of Mechanical Equipment Reliability Assessment of the Development and Thinking of," Mechanical Engineering, Vol. 50, No. 2, pp. 171-186, 2014

12. G. Q. Wang, Z. M. Wang, J. G. Yang, et al., "Reliability Assessment of Multiple NC Machine Tools with Minimal Repair," Journal of Harbin Institute of Technology, Vol. 43, No. 7, pp. 127-130, 2011

13. Q. B. Hao, "Fuzzy Comprehensive Distribution and Prediction of Reliability and Maintainability of CNC Machine Tools," Jilin University, Changchun, 2012

14. Y. Qin, K. Wang, and H. X. Yin, "Reliability Analysis of Subway Vehicles based on the Data of Operational Failures," EURASIP Journal on Wireless Communications and Networking, Vol. 2017, No. 1, pp. 1-8, 2017

15. J. L. Wang, "Reliability Growth Design based on Reliability Allocation and Prediction for High Speed Precision Stamping Machine Tools," Jilin University, Changchun, 2014

16. D. K. Liu, H. B. Lin, and Q. Li, "Fatigue Reliability Model of Bogie Frame Structure for High Speed Train," China Railway Science, No. 5, pp. 100-106, 2017

17. F. Li, H. L. Li, and S. P. Pan, "Low Dynamic Performance and Connection Reliability of New Truck Radial Bogies," Journal of Transportation and Transportation Engineering, No. 5, pp. 39-46, 2013

18. S. Lin, W. T. Li, and Y. Qin, "Research on Safety and Reliability Analysis and Evaluation Method of High-Speed Train System," Electric Drive of Locomotive, No. 1, pp. 6-13, 2016

19. M. Karaulova, T. Kostina, and E. Shevtshenko, "Reliability Assessment of Manufacturing Processes," International Journal of Industrial Engineering and Management, Vol. 3, No. 3, pp. 143-151, 2012 